\title{
0 problema epistemológico da ciência litúrgica e a hermenêutica do Vaticano II
}

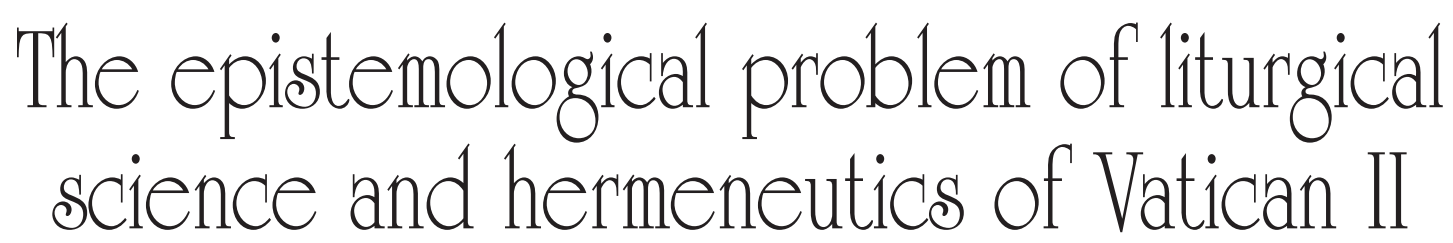

Manoel Pacheco de Freitas Neto*

Resumo: A pesquisa epistemológica no campo da ciência litúrgica e a hermenêutica do Vaticano II é o tema de estudo deste texto, que será estruturada para tratar a relação ciência litúrgica e ciências humanas. Partindo do pensamento do Vaticano II, nos esforçaremos para delinear um plano hermenêutico contido em seus próprios textos, classificando determinadas categorias conceituais que nos conduzirão com segurança corresponder com a proposta do Concílio: que é aquela de cultivar com precisão metodológica e cientifica, um diálogo contínuo com as ciências humanas. Nossa área de leitura parte das referências decisivas, presentes no documento da Sacrosanctum Concilium; definiremos o objeto da ciência litúrgica com evidente ênfase do fato antropológico; apresentaremos a pesquisa promovida pelo Concílio e indicaremos alguns modelos a nível epistemológico: 0 histórico e o teológico e concluiremos com uma proposta metodológica em base aos maiores estudiosos da liturgia cristã de nosso tempo.

Palavras-chave: Liturgia; Epistemologia; Hermenêutica; Concílio; Sacrosanctum Concilium.

Abstract: The epistemological research in the field of liturgical science and hermeneutics of Vatican II is the subject of study of this text, which will be structured to address the relationship between liturgical and

\footnotetext{
* Doutor em Teologia pelo Pontifício Ateneo de Santo Anselmo - Roma, Itália. Estudou Ritos das Igrejas Orientais (livre) no Patriarcado Latino de Jerusalém. Professor titular da Faculdade de Teologia João Paulo II, FAJOPA, Marília, SP. Assessor da Formação Cristã na Diocese de Assis. E-mail: manoel.antioquia@gmail.com
} 
humanities science. Based on the thought of Vatican II, we strive to outline a hermeneutic plan contained in their own texts, classifying certain conceptual categories that will lead us safely correspond with the Council's proposal, which is that of cultivating with methodological and scientific precision, an ongoing dialogue with the humanities. Our reading area of the decisive references present in the document of Sacrosanctum Concilium; We define the object of liturgical science with obvious emphasis of the anthropological fact; We present the research promoted by the Council and indicate some models on the epistemological level: the historical and the theological and conclude with a methodology based on the greatest scholars of Christian liturgy of our time.

Keywords: Liturgy; Epistemology; Hermeneutics; Council; Sacrosanctum Concilium.

\section{A estabilidade de um método}

A Liturgia superou a conceituação de disciplina jurídica orientada para a regência das aplicações legislativas referentes às rubricas e os cerimoniais, e que, portanto, não apresentava nenhum interesse teorético. Superou, também, a crítica dos “hábitos exotéricos”, porque tudo o que caiu no seu domínio não podia ser verificado e reconquistou a sua dignidade de disciplina teológico-espiritual.

Esta aquisição do Concílio é o resultado de um desenvolvimento cultural que obteve no Movimento Litúrgico e na Encíclica de Pio XII Mediator Dei (20.11.1947) sua etapa mais significativa de penetrante releitura teológica.

Todavia, neste processo de emancipação, a Liturgia não soube elaborar um aceitável modelo epistemológico que legitimasse sua própria dignidade cientifica, assumindo ingenuamente o estratagema escrito por Beckett ${ }^{1}$, confiando a própria credibilidade às afirmações da ciência dogmática.

1 BECKETT, S. Compagnia e Worstward. Milano : Jaca Book, 1986, p. 27. 
Nos anos sucessivos ao Concílio, os esforços empregados para a divulgação correta da reforma litúrgica na vida da Igreja, obteve no Convênio Internacional de Assis² (1986), uma importante conclusão sobre o valor das ciências humanas no âmbito do culto cristão: Em particular é necessário aceitar o confronto com as ciências humanas, dando espaço na pesquisa litúrgica àqueles critérios metodológicos e epistemológicos que tais ciências estão elaborando com sabedoria e ultimamente aplicando. Todavia, não se trata de reduzir a ciência litúrgica, a pura ciência humana; mas se trata de adquirir novos instrumentos de pesquisa e de análise. Isto é o que pensamos e tentaremos redigir na presente leitura: legitimar a relação entre liturgia e ciências humanas a partir de um implante epistemológico.

A epistemologia é propriamente a filosofia da ciência, isto é, a disciplina que tenta reconstruir os pressupostos sobre os quais a ciência funda suas próprias certezas. Essa não concerne somente à apologética do existente, mas também compreende uma tarefa crítica para desmascarar as mistificações ideológicas por traz do simulacro moderno da "cientificidade", abrindo assim uma brecha na sistemática do fundamento, isto é, na reflexão sobre o que torna "científica" uma ciência.

Quais são os critérios sobre os quais uma ciência possa legitimar sua teoria?

E sobre quais bases verdadeiras se apoiam tais critérios?

Desde quando desabaram as certezas do positivismo do século passado, se assiste a ruína e a inclinação de suas linhas anárquicas. P.K. Feyerbend, última voz no debate epistemológico, afirma: "A ciência é uma imprensa essencialmente anárquica: o anarquismo teorético é mais humanitário e mais aberto a encorajar o progresso que não as suas alternativas fundadas sobre a lei e sobre a ordem”3.

Não obstante esses sinais radicais, o pensamento histórico não entende renunciar a um dos caracteres mais singulares da nossa cultura: a pretensão da verdade da ciência. Desde quando o sentido

2 Cf. O Movimento Litúrgico tra riforma conciliare e attese del popolo di Dio, Assisi 19561986. Documento finale, "Rivista litúrgica" 74, 1987, p. 152.

3 FEYERBEND, P.K. Contro il método. Milano: Felttrinelli, 1980, p. 15. 
primário do Logos é o se dar conta da exposição intelectiva da causa, a ciência é um peculiar caráter de atuação da "cura” do ser-no-mundo".

De fato tudo o que vem conhecido em base a causa, mediante a indicação da mesma, passa a ser disponível no seu ser também para o outro. O ser para a coisa é o saber, que avança necessariamente a pretensão da comunicabilidade, para que a sua volta, pode também ser pretendido do outro em modo que à luz da causa ou do ente resulte compreensível a todos os seres ${ }^{5}$.

Uma das razões, não secundárias, do desvanecimento da liturgia para o homem contemporâneo é que o culto se exprime em uma linguagem para os iniciados, que não é compreendida universalmente nem mesmo na sua gramática de nível elementar. As ciências humanas permitem aos outros campos dialogar, por isso o outro passa a ser uma das tarefas primárias da pesquisa epistemológica e do recupero do sentido litúrgico.

Não podemos percorrer o amplo e complexo debate da disciplina epistemológica segundo o seu status contemporâneo, pois nos limitaremos a especificar as problemáticas que persistem diretamente no campo da ciência litúrgica e, que estimulam novos horizontes de pesquisa e apostam na estabilidade metodológica proposta por nossos autores.

\section{0 objeto da ciência litúrgica}

A partir do momento que cada ciência se especifica por seu objeto próprio, é indispensável fixar aquele da teologia litúrgica como ilustraremos, em modo mais articulado a seguir, que é a praxe celebrativa da Igreja, através da qual tentaremos alcançar o nosso objetivo: aquele de reconhecer o estatuto de uma teologia litúrgica fundamental, que entende dar razão a experiência mistagógica do culto cristão, em vista da admissão do fato antropológico no quadro teológico, esse ultimo deve corresponder de modo estável, isto é, não

\footnotetext{
ARISTÓTELES, Metafísica. Torino,UTET,1974, II, 20, p. 230

5 GADAMER, H.G. Studi Platonici. Marietti: Casale Monferrato, 1983, p. 24.
} 
como espectador, aos requerimentos da ciência compreendida como interrogação sobre seu fundamento.

As coordenadas do Concilio Vaticano II globalmente superaram a visão rubricista da liturgia e aprofundaram sua validade teológica declinando-a com as instâncias pastorais, sinalizando com maior reprise que o modo específico do culto Cristão de mediar a salvação é a ritualidade. Este modelo nos permitirá atingir o alvo epistemológico decisivo que nos apoiará a assumir uma releitura do rito em prospectiva fenomenológica simbólico-lúdica.

Percorramos uma rápida leitura do Concílio:

- O objeto da ciência litúrgica é o rito, nas ações litúrgicas está presente Cristo. Cristo é sempre presente na sua Igreja, em modo especial nas ações litúrgicas. E presente no sacrifício da missa seja na pessoa do ministro, seja, sobretudo, nas espécies eucarísticas. E presente com a sua virtude nos sacramentos. E presente na sua palavra; e presente enfim quando a Igreja toda ora e louva (SC 7).

- A multiplicidade da presença de Cristo na Igreja eleva o complexo problema da relação entre sacramentalidade em geral e sacramentos, isto é, o problema do especifico modo de transmitir a Graça nas diversas mediações sacramentais. A liturgia parece mediar a relação com Cristo através da ação ritual ou da ação sagrada, a mais eficaz entre as ações eclesiais em ordem a salvação (SC 7).

- A liturgia é atuação do Mistério Pascal por virtude do Espírito Santo através de um rito de convivência: "Todas as vezes que comemos a ceia do Senhor, proclamamos a morte do Senhor até que Ele venha”. Desde Pentecostes, a Igreja nunca mais deixou de reunir-se em assembleia para celebrar o mistério pascal: com a leitura, com a celebração da eucaristia, na qual veem representados a vitória e o triunfo de Cristo sobre a morte (SC 6).

A representação da vitória de Cristo sobre a morte se exprime através da ceia pascal, isto é através de um rito.

c) "A liturgia é o exercício do oficio sacerdotal de Jesus mediante o qual com sinais sensíveis vem significada e, em modo próprio a cada um, realiza a santificação do homem, e vem exercido pelo corpo místico de Jesus Cristo, da cabeça do corpo e de seus membros, o culto público integral” (SC 7). Retorna o tema da mediação salvífica 
do sacerdócio de Cristo que é realizado mediante "sinais sensíveis". $\mathrm{Na}$ liturgia, a história da salvação se ritualiza por meio do sacrifício e dos sacramentos; é outra preciosa indicação sobre o modo específico no qual o Espírito se encarna no culto, e uma pista clara para o desenvolvimento de nosso estudo.

No número 5 SC lemos: "Do lado de Cristo sobre a cruz jorrou o admirável sacramento de toda Igreja”.

Entendendo o sacramento segundo a Sacrosanctum Concilium como mediador de Deus e dos homens, perguntamos em qual sentido Cristo Jesus é sacramento na Igreja e aos sete sacramentos? Evidentemente, a analogia Cristo e a Igreja se deve indicar um critério para a interpretação da liturgia. Nesse sentido a liturgia: [...] Contribui ao sumo grau para que os fiéis exprimam em suas vidas e manifestem aos outros o mistério de Cristo e a genuína natureza da verdadeira Igreja, que tem a característica de ser ao mesmo tempo humana e divina, visível, mas, dotada de realidade invisível, ardente na ação e detida na contemplação, presente no mundo e, todavia, peregrina. (SC 2) Cristo, Igreja e liturgia são intimamente inseparáveis no dinamismo dialético sacramental: visível-invisível, humano-divino, presença-ausência. Todavia, o elemento visível que especifica a mediação salvífica da liturgia tem sua própria consistência e autonomia a respeito de Cristo e da Igreja e é representado na ritualidade. "Per ritus et preces", rebate o n. 48 da SC "se participa ao Mistério da Fé no culto".

O objeto próprio da ciência litúrgica é, portanto, o rito que se registra no fundamental dinamismo da relação sacramental de Cristo e da Igreja, mas mantém uma própria configuração antropológico-cultural.

Ora, o polo visível da dialética sacramental é constituído dos elementos disponíveis no âmbito histórico-cultural: os elementos da natureza, como a água, dado de um esquema cultural que, interpretado emerge e reproduz a originalidade de um conteúdo de crença.

Portanto, a fidelidade da Igreja ao sacramento percorre esta via da cultura e de sua historia. A natureza sacramental da Igreja é inserida na exigência pastoral de adaptação e de criatividade e esta exigência toca diretamente a liturgia.

No proêmio da Sacrosanctum Concilio n. 1 se registra já esta intenção: em síntese conduz a reflexão teológica a examinar o fato 
do encarnar-se da graça no culto nas formas histórico-rituais é um dever teológico pesquisar sobre as formas do culto para favorecer uma autentica reforma.

O texto de n. 21 da SC é fundamental para o nosso interesse de pesquisa epistemológico e aponta rigorosas observações: Antes de tudo como destacar os elementos imutáveis, de origem divina, daqueles suscetíveis a mudança? Supomos que de instituição divina, no culto, são aqueles revelados e atestados pela Sagrada Escritura como a Última Ceia que tomamos como modelo dissertativo:

\subsection{0 corpo e o sangue - da antropologia ao mistério}

Sabemos, porém, que os Evangelhos são livros de fé da Igreja e não uma reconstrução fidelíssima das ipsissima verba et facta Iesu; em consequência disso, o rito da Última Ceia pascal narrado no Novo Testamento faz já parte da tradição eclesial e não tem nenhuma garantia especial de originalidade à praxe do Jesus histórico a respeito das sucessivas reformas. Se bem que a Igreja atribua uma singular autoridade à experiência de fé apostólica, como é transmitida nos Evangelhos. Todavia, é consciente que sua normativa não é vinculada à reconstrução histórica da Última Ceia de Jesus, mas é testemunho da comunidade primitiva, assim como o Kerygma que interpela os homens não é aquele do Jesus histórico reconhecido dos exegetas, mas daquele predicado pelos apóstolos.

Sobre as “palavras da instituição”, escreve G. Bornkamn: "podem assumir um significado sacramental somente a partir da morte de Jesus, não só iminente, mas já acontecida, e do seu significado salvífico assim como é compreendido da comunidade pós-pascal”.

O comento provocatório de I. Schniewind: "Aquilo que aconteceu na quinta-feira santa, não nos inclui em nenhum modo" a ser luminoso, se excluirmos naturalmente uma acentuação bultmaniana demasiada que marginaliza cada interesse pelo dado histórico. Ora, a Formgeschichte nos conduziu a importância do Sitz im Leben na elaboração de uma perícope e nos demonstrou que os fatores

6 BORNKAMN, G. Storia e Fede. Bologna: EDB, 1970, p. 24.

7 SCHNIEWIND, I. Leitourgia e Mistero. Milano : Jack Book, 1972, p.207. 
contingentes e históricos formam uma unidade indeteriorável com as verdades reveladas. A verificabilidade é apresentada pelos diferentes textos que descrevem a Última Ceia e apresentam variantes assim notáveis que rendem quase não irreconhecível o evento fundante. Portanto, os ritos e suas estruturas pertencem ao tempo da Igreja e não é simples distinguir os elementos de instituição divina daqueles de competência humana.

Se o texto do Concilio entende dizer, como presumimos que na liturgia existe um núcleo específico e sempre idêntico que vai salvaguardado na descontinuidade dos tempos e das situações culturais, isto é o mistério pascal da morte e ressurreição do Senhor e todos os demais campos da ritualidade são suscetíveis às mudanças e adaptações, então emergem outras e mais radicais interrogativas: A competência da Igreja é absoluta e sem pressupostos, mas, como em todos os campos a Igreja deve respeitar o estatuto da Criação para poder mediar a redenção, assim a liturgia deve salvaguardar a especificidade da linguagem ritual para poder acessar o mistério de Cristo. No confronto da condição humana, Cristo se submeteu às regras do jogo do ser no mundo: nasceu, cresceu, trabalhou, lutou, chorou, se irritou, amou, teve amigos e adversários, é morto. E quando quis confiar memorialmente a nova aliança aos discípulos, não inventou nada ex novo, mas se serve do ritual pascal hebraico como linguagem apta para ritualizar a intervenção definitiva de Deus na historia. Desde modo, ele se insere com continuidade de método na divina economia, na descontinuidade de conteúdo da sombra para a verdade.

Os estudiosos, hoje, não se permitem contestar a origem hebraica da ceia pascal de Jesus, justamente se reconhece que Ele re-significou referindo-a a sua morte. Jesus não fez nenhuma outra coisa a não ser percorrer tudo aquilo que já havia acontecido no tempo do Êxodo. A documentação desta afirmação é muito ampla: “ Le langage eucharistique reste éminemment judéo-chrétien, dans la ligne dês repas de communion de l'ancienne alliance. Le eucharistie “ accomplit” l'eucharistie juive, dans mouvente de continuité à la fois suivant la ligne thèologique de l'épitre aux Hébreux. Comme le dit l'auter de cette épitre dans He 13,15, la communauté continue d'offrir le “ sacrifice 
de louange " ou todah, dans " l'offrande des lèvres " qui proclame efficacement le salut - omologein - dans la persona de Jésus" 8 .

No tempo do Êxodo, segundo a documentação G. Fohrer" ${ }^{9}$, os hebreus praticavam magias de origem cananeia, como são narradas no Antigo Testamento; o sacrifício anual a Azazel para obter a proteção (Lv 16); as ofertas aos demônios para a fertilidade dos campos (Lv 19,9); as práticas de adivinhação (2 Rs 21,6); costumes fúnebres como rasgar as vestes (Lv 10,6; 2 Sm 1,2.11; 13,31; 13,31; 2 Rs 19,1), sentar sobre cinzas (Jr 6,26; Mq 1,10); o saneamento das fontes poluídas com sal (2 Rs 2,19s) e dos alimentos envenenados com farinha (2 Rs 4,28s); o influxo sobre as ovelhas (Jr 30,37s.). No círculo da Palestina, permaneceram ancoradas as ideias nômades e a crítica dos profetas provocou uma batalha campal contra as bruxarias (Ex 22,17; Dt 18,10s.; 2Rs 11). Grande parte do patrimônio israelita sacrifical se desenvolveu sob influência cananeia. Todavia, todo esse complexo não se infiltrou em nome das divindades cananeias no mundo hebreu, mas em nome do Deus dos Patriarcas de Israel. A partir de um modelo cultural, são realizadas tantas estratificações, cada uma com sua própria intencionalidade específica e aplicada ao conteúdo que devem traduzir, mas todas fazem referência ao mesmo códice linguístico, isto é, à experiência ritual que visualiza o mistério.

O Concílio Vaticano II evidenciando, de uma parte, o valor soteriológico da liturgia e, da outra parte, a necessidade de uma reforma dos ritos, reconheceu a estreita correlação entre essas duas dimensões. Um rito sem referencia cristológica é só uma peça teatral, que inevitavelmente desemboca no formalismo e no esoterismo cerimonial. Ao contrário, uma pura intenção cristológica que se desinteressa do rito, porque este é secundário, não de necessitate, resultará no esvaziamento e esterilização dos gestos que comunicam o efeito da graça.

8 C. PERROT, Le repas du Seigneur, «La Maison-Dieu » 123 (1975) 29-46. A abordagem da pesquisa sobre as práticas dos ritos pagãos no ambiente israelítico encontra uma ampla extensão nas documentações de Fohrer, o retrato que vem composto neste trabalho, reflete com clareza a imagem necessária do recurso lingüístico e simbólico provenientes de outras noções culturais para aplicar uma hermenêutica na formação do conceito do sagrado em Israel.

9 FOHRER, G. Strutture teologiche dell'Antigo Testamento. Brescia: Padéia, 1980, p. 81. 
A história do culto cristão no ocidente sinaliza com convicção pontual estes riscos: O rubricismo dos pontificais medievais, o exasperado gosto cenográfico e barroco esconderam e sufocaram a referência pascal na consciência dos fiéis, enfatizando o elemento de preceito e provocando a explosão do rito em uma mera dimensão espetacular. Do outro lado, a limitada atenção às sequências rituais entregues à improvisação, no nosso tempo, permitiu a cada um a inexaurível "febre" mitopoiética do alegorismo que produziu a implosão do rito na liturgia, e não reage mais aos abusos subjetivos e ao saqueamento da "devotio".

O Concílio reconhece a necessidade de uma reforma das partes que, no curso do tempo, podem e devem oferecer mudanças. No momento em que são verificadas insinuações menos correspondentes à íntima natureza da liturgia, vale a tese segundo a qual a graça na liturgia se rende acessível aos fiéis somente se se respeita a linguagem ritual no seu singular e autônomo modo de encarnar o Espírito. ${ }^{10} \mathrm{Se}$ no curso da historia a liturgia não é mais uma pista na qual percorre a piedade do povo cristão e cessou de ser lugar mistagógico para o encontro vivo com o Ressuscitado - e o Concílio parece tomar ato -, isto significa que o desfalecimento da linguagem ritual coincide com o desfalecimento do Objeto imenso do qual é portador.

Trata-se de estabelecer em base a quais critérios se reformam o culto. O Magistério não evitou a pergunta: quais são as condições de celebração da liturgia cristã? O Vaticano II não formulou uma resposta

\footnotetext{
10 A tese encontra seu recurso principal de defesa e autenticidade no quadro litúrgico da última ceia. A liturgia cristã aprofundou suas raízes na liturgia judaica, todavia não se trata de desenvolver um plano teoretico demonstrando que Jesus, enquanto um Judeu, foi conduzido e orientado pela sua cultura fundar a sua memória para os seus discípulos, se servindo dos elementos rituais hebraicos, trata-se de observar aqui um dado a priori, isto é, a epifania de um mistério que esta se desenvolvendo. Em relação ao qual Israel o reconhece na sua historia (êxodo) e o celebra em sua linguagem ritual. Jesus se insere neste horizonte epifanico, já existente e, através da linguagem ritual hebraica, eleva esse fato ao estado de realização plena e definitiva, isto é, o revelatório, re-significando tudo. O rito - antiga e nova aliança - aparece como dinâmica pedagógica da gradual exposição do mistério divino. A quantidade de estudos sobre o tema é imponente: GIRAUDO,C. La struttura letteraria della preghiera eucarística. Saggio sulla genesi di uma forma, Romam Biblical Institute Press, Roma 1981, p. 4. Ver tambèm: JEREMIAS, J. Le parole dell'ultima ceia, Paideia Brescia, 1973 (Biblioteca de Cultura Religiosa 23); H. CAZELLES, Eucharistie, bénédiction et sacrifice dans l’Ancien Testament, “La Maison-Dieu” 123 (1975) 7-28; sobretudo PERROT, C., Les repas du Seignnneur, “La Maison-Dieu” 123 (1975) 29-46.
} 
articulada a propósito; mas reenviou ao pós-concilio a atuação da reforma. Todavia, nas normas para a ativa participação dos fiéis e, para a adaptação às índoles religiosas dos povos, podemos extrair algumas interessantes indicações: "Para promover a participação ativa, cuidem da aclamação do povo, as respostas, a salmodia, as antífonas, os cantos, ações e gestos e o comportamento do corpo. Observe o devido tempo, o silêncio sagrado" (SC 30).

Podemos precisar com segurança que é competência da Igreja, estabelecer quais os gestos simbólicos que podem traduzir adequadamente o mistério de Cristo ${ }^{11}$. O conceito de sacramento em Santo Agostinho, examinado por E. Ruffini intervém quando afirma: A simbolicidade que contém o ordo salutis transcende e supera aquela que pertence ao ordo creationis, mas, enquanto a transcende, não invalida e nem a desvaloriza, mas às consente uma maior e plena realização. Este dado de fato, consentira Agostinho de chegar à importante conclusão que também a simbolicidade pré-cristã podia ser veiculo e nascente de salvação, a nós consente afirmar que no sistema agostiniano, a verdadeira raiz simbólica é o homem. A economia salvifica é a dimensão simbólico-sacramental não tanto pela força de uma norma de um soberano ou de um decreto emanado pelas divindades, mas em força de uma profunda fidelidade de Deus à antropologia ${ }^{12}$.

Para admitir algum elemento estranho na liturgia, a Igreja deve presumir que existam formas rituais em outras culturas capazes de traduzir o mistério pascal. Então para uma reforma litúrgica precisa colocar-se escrupulosamente diante desse controle de caráter antropológico, em que se verifica como as formas rituais devem legitimar suas capacidades mistagógicas. A esta tarefa, o Concílio chama "pastoral”. A Igreja deve deixar-se inspirar pelas ciências humanas para descobrir as condições de celebrabilidade da liturgia. Este critério é inédito, todavia hoje resulta indispensável. Não possuía uma crítica

11 Segundo Meyer, não obstante todos os mutamentos históricos, os elementos da liturgia que são imutáveis se apoiam com efeito na instituição divina, MEYER, H. Elementi Mutabili ed elementi vincolanti nella forme liturgiche. Concilium, Milano, v. 5, n. 1, pp 63-64.

12 RUFFINI, E. Teologia dei sacramenti e liturgia in teologia e liturgia : rapporti interdisciplinare e metodologici. Bologna: EDB, 1974, p. 139. 
histórica, legitimava a praxe corrente considerando que o fato foi sempre assim. Foi a crítica moderna que documentou as radicais mudanças, que se sucederam ao longo do século, sem ulterior prognóstico sobre a nova tarefa de estabelecer os critérios da reforma. A SC não toca explicitamente a pista antropológica, todavia orienta nesta direção quando afirma: "Para conservar a santa tradição abrir, porém a vista de um legítimo progresso, a revisão das partes singulares da liturgia deve ser sempre precedida por uma apurada investigação teológica, histórica e pastoral” (SC 23). O que significa investigar a liturgia em modo pastoral? A resposta poderá vir com clareza desde conceito, segundo as indicações do Concílio à famosa nota 1 da GS: A Constituição pastoral - A Igreja no mundo contemporâneo consta de duas partes, mas é um tudo unitário. Vem descrita pastoral porque sobre a base dos princípios doutrinais entende expor o comportamento da Igreja em relação ao mundo e aos homens de hoje. Portanto, não é a primeira parte em que falta a intenção pastoral, nem a segunda intenção doutrinal...

Em breve, a pastoral é sujeita a uma dúplice pertença e vinculada a uma dúplice fidelidade: a Deus e ao homem. Este vínculo é intrínseco e por este motivo, a análise da situação do mundo, conduzida pelas ciências humanas, entra em pleno título no estatuto epistemológico da pastoral, e nem por isso perde sua dignidade teológica. Neste sentido sustenta Chenu afirmando que a teologia será mais teologia dando espaço às ciências humanas ${ }^{13}$.

Estudar a nível pastoral a liturgia significa assumir o homem concreto, com as suas raízes e capacidades, conhecer sua pré-compreensão para encontrar suas condições de celebração e tentar convencer os alérgicos ao culto sobre a sua necessidade em ordem a experiência religiosa. Mais especificamente, significa contribuir para legitimar ao homem, que não compreende mais a liturgia, o porquê é necessário o rito para entrar em contato com Deus; esta é já uma pré-compreensão que perdemos em modo irremediável, isto é, a "ingênua"

13 CHENU, M.D. Pour une Anthropologie sacramentelle? La Maison-Dieu, Paris, v. 3, n. 71, jan. 1974. Bimestral, pp 85-100. 
imanência com os sinais do sagrado ${ }^{14}$ como primeira hermenêutica. A tarefa primaria é exibir a verdade sobre o rito, isto é, justificar como a linguagem ritual é capaz de mediar o evento escatológico da morte e ressurreição do Senhor. Esta legitimação será possível se o rito, indagado com metodologias antropológicas, demonstrar as razões do seu poder mistagógico.

O quesito fundamental então é: porque celebrar? Tal gênero de pergunta não consente resposta endogene; quando o liturgista se interroga sobre o "porque", deve necessariamente confrontar-se com o inteiro cosmo humano para estabelecer o sentido que esse compreende para a liturgia. Este confronto não seria efetivo se não encontrasse como base a atenção das ciências humanas que estudam o cosmo humano. A solução do "porque" a liturgia se interessa pelas ciências humanas é incindível: o verdadeiro e mais profundo "porque”, de fato, é o interesse das condições antropológicas que rendem sensato o celebrar litúrgico.

Isto não significa contraste com a autoridade da Igreja, que "unicamente" tem a competência em matéria litúrgica ${ }^{15}$, mas simplesmente oferecer um contributo para exercitar este ofício. Que a relação entre autoridade competente e ciência litúrgica se possa resolver, assim como em outros campos da teologia. A ciência teológica de fato não pode e não quer substituir o magistério ou as suas exigências de guia, antes

\footnotetext{
14 É explicito o comportamento de membros da Igreja, que são provas evidentes de um comportamento no qual a noção do sagrado e seus sinais se esvaziaram de suas experiências religiosas. Bastam simples observações como o silêncio dentro do templo que não existe e demonstra que perdemos a sensibilidade que devemos manifestar quando nos encontramos diante de um mistério. O trânsito diante do altar para todos os lados (muitas vezes sem referência) parece que estamos dentro de nossas casas e não em um lugar de culto e adoração. Objetos que são colocados sobre o altar, denunciam amargamente a ausência do sentido e da percepção do sagrado em nosso meio. Sobretudo a relação que assistimos, em grande parte, com o templo é uma relação secularizada e profana. 0 altar do Santo Sacrifício que celebra a nossa Redenção, muitas vezes, parece uma mesa qualquer e o templo, enquanto casa de oração, outro lugar qualquer, porque o comportamento que devemos manifestar diante das realidades sagradas são ausentes. A percepção do sagrado vem ignorada por falta de uma revisão a nível educativo do comportamento religioso católico, a observação mais crítica é que não deveria ser necessária esta real constatação, porque vivemos dentro de um riquíssimo patrimônio antropológico-cultural (Brasil), no qual o horizonte do sagrado se exprime como experiência off limits.

15 cf. SC 22
} 
o deve respeitar sua função ministerial. Como as outras disciplinas também a ciência litúrgica apresenta os resultados científicos, mas deve remeter a outros a decisão que os aplica ${ }^{16}$.

Conclusão sobre o Concílio: O modelo epistemológico da liturgia subjacente a SC é ainda hoje o mais avançado, não só por sua incontestada autoridade do magistério, mas pela sua objetiva competência crítica. Parece-me fecundo traçar sinteticamente o quadro para uma reprise criativa dos pontos abertos deixados pelo Concílio.

- A liturgia é sacramento de salvação.

- O especifico da sacramentalidade litúrgica é a ritualidade.

- O objeto específico da ciência litúrgica é o rito.

- O rito, enquanto fenômeno cultural, pertence às realidades mutáveis e históricas.

Vem estudada como disciplina pastoral em base a competência das ciências humanas.

O problema epistemológico crucial da liturgia implícito nos documentos conciliares é, portanto, o problema da fundação antropológico-transcendental do rito, como linguagem capaz de comunicar o Mistério Pascal.

\section{Desenvolvimento da pesquisa promovida pelo Concílio}

A tarefa que herdamos é a construção de uma liturgia fundamental, onde se investigam do ponto de unidade transcendental as condições de possibilidade do dar-se da salvação no rito. Trata-se em definitiva de alargar a liturgia ao método da teologia fundamental, como resulta na obra teológica contemporânea mais prestigiosa, Mysterim Salutis. Como categoria teológica, "história da salvação" quer exprimir sinteticamente o dinamismo da Revelação, se é cercado o seu fundamento antropológico no estudo das condições de possibilidade do advento do Espírito na história e se é indagada sobre o nódulo transcendental da historicidade, para dar legitimação científica à

16 RENNINGS, H. La scienza liturgica. Concilium, Milano, v. 5, n. 2, giun. 1969, pp 155-156. 
teologia ${ }^{17}$, assim o culto cristão precisa aprofundar a nível transcendental as condições de possibilidade do conceder-se do Espírito na ritualidade, para fundar e, portanto, legitimar cientificamente a disciplina litúrgica. Esta hermenêutica transcendental é que ativa a compreensão do rito e deve ser precedida pela fenomenologia do rito, que pretende um mais positivo apreender do fato ritual.

Globalmente, o Concílio solicita uma verificação "transcendental" sobre o "fenômeno" rito, para descobrir a sua verdade. Essa, portanto, não deve aventurar-se na área litúrgico-cristã se não no final da redação, inserindo o método fundativo-transcendental ao método teológico-litúrgico; deve permanecer no campo periférico, sem referimento explícito dos conteúdos cristológicos.0 método entende demonstrar as condições de possibilidade do conceder-se do Mistério Pascal na Liturgia, se moverá no quadro da teologia fundamental para imigrar verso a conceituação qualificada, baseada pelo seu referente mistagógico: o Cristo morto e ressuscitado, mas que se registra no rito o Seu Mistério.

A nova tarefa promovida pelo Concilio consiste no mostrar porque o Evento Pascal se dá na liturgia em modo ritual ${ }^{18}$. A atenção deve concentrar-se sobre o canal da graça, não sobre a graça em si. $\mathrm{O}$ rito é como o ar em que a liturgia encontra seu respiro. Trata-se de descobrir a razão do porque não podemos não celebrar, porque não podemos eliminar a mediação ritual se queremos aceder ao Mistério. Esta investigação cultiva a presunção de uma resposta sobre a pergunta: Porque o rito? Qual é o significado do rito? É uma preocupação essencialmente hermenêutica. A tarefa hermenêutica se impõe

\footnotetext{
17 DARLAP, A. Mysterium Salutis: compendio di dogmatica storico-salvifica. Brescia: Queriana, 1974, v.1/2, pp. 33-221.

18 Se rende enfim necessária uma especificação terminológica de "rito" e de "liturgia" na nossa leitura. O rito religioso é um fenômeno complexo de ações, pessoas, objetos, palavras, lugares, tempo, templo, que colocam o humano em relação com um mundo superior. A liturgia, o culto cristão é "uma ação sagrada, através da qual, com um rito, na igreja e mediante a igreja, vem exercitada e continuada a obra sacerdotal de Cristo. Para maior aprofundamento leiam: RIZZI, A. Differenza e responsabilità. Saggi di antropologia teológica, Marietti, Casale Monferrato, 1983, p. 111.MARSILI,S. Liturgia, in Nuovo Dizionario di Liturgia, Edizioni Paoline, Roma, 1984, p. 733.GADAMER, H.G. Ermeneutica e metódica universale, Marietti, Torino, 1973, p. 51. (Classici Del pensiero moderno e contemporâneo 4).
} 
quando a tradição é em crise, quando é insuficiente, quando aponta respostas velhas às perguntas novas, quando um paradigma mostra sua rachadura, quando temos clara consciência da necessidade de captar uma distância e de superar uma alteridade, para construir uma ponte entre passado e presente ${ }^{19}$.

No nosso tempo existe uma indiscutível fratura na compreensão do fato ritual em respeito a tradição que o transmitiu. Os ritos são talvez interpretações da condição de uma mentalidade pré-crítica? Não foram vistos como instrumentos do poder e de conservação? Não aparecem em grande parte, formais, exteriores e vazios? Muitas vezes parece ambientar a magia, a superstição, produzindo de consequência a des-responsabilidade social? São interrogações que merecem uma atenta consideração, se queremos evitar uma extenuação inexorável do sentido do culto cristão.

\section{Modelos epistemológicos da liturgia}

A linha epistemológica do Concílio, que orienta a liturgia verso o plano pastoral é o primeiro ponto de conclusão de um longo processo de reflexão, que se identifica com o Movimento litúrgico. Ao mesmo tempo indica um novo ponto de partida para a definição do elenco dos principais modelos, que entendemos demonstrar, qualificados como os mais consistentes criticamente e sustentável para melhor especificar a validade de uma pesquisa para uma teologia litúrgica fundamental: o modelo histórico e o modelo teológico.

Modelo histórico: Na tentativa de superar a concepção rubricista, que separava a forma do conteúdo com o nítido prevalecimento do aspecto exterior sobre a dimensão interior, já se posicionam diversos estudiosos que definiram em termos positivos e históricos a liturgia: "Na sua natura de ciência positiva" - escreve Eisenhofer ${ }^{20}$ - "deve tratar dos singulares atos do culto, quais são estabelecidos da legislação litúrgica, estudando-os em seus significados históricos e em seus significados objetivos”.

19 GADAMER, H.G. Ermeneutica e metodica universal. Torino : Marietti, 1973, p. 51.

20 EISENHOFER, L. Compendio di Liturgia. Torino : Marietti, 1941, p. 6 
E prossegue: "A liturgia é uma ciência autônoma, com seu próprio objeto, o culto estabelecido por Cristo para a Igreja, e um próprio método histórico exegético" 21.

Este comportamento positivístico, que repõe o sentido da liturgia para sua compreensão no presente, é paradigmático, por exemplo, no Líber Sacramentorum (1920) de I. Schuste ${ }^{22}$.

“Toda a teologia é condensada nas venerandas e arcaicas fórmulas romanas do divino sacrifício" 23 .

A mesma inspiração anima o Manual de historia litúrgica (19451953) de M. Righetti, que define a liturgia "uma seção da história eclesiástica": "Sua esfera de competência são todos os elementos que tem relação com o culto e principalmente com suas origens, seus desenvolvimentos históricos, em si mesmo e em relação ao ambiente no qual se constituíram" ${ }^{24}$.

Para a direção dessa pesquisa em primeiro lugar não contamos com os singulares fenômenos (Missa, Breviário, Ano Litúrgico, etc), mas principalmente com a história da totalidade litúrgica, da vida e da espiritualidade da liturgia, dos desenvolvimentos, das mudanças, e também dos exageros das formas litúrgicas. Entendemos expor, através dos exames de diversas épocas culturais, como o culto da Igreja de Deus foi encarnado e se exprimiu em uma cultura própria e assim em cada época, e como de uma a outra parte foi capaz de influenciar tais culturas e transformá-las ${ }^{25}$.

A este ponto, a instância hermenêutica é evidente: a mais global compreensão do fenômeno litúrgico individuado nas coordenadas culturais fornece a chave de leitura dos fatos particulares e, sobretudo, um critério fundamental para a vida litúrgica do presente. A relação liturgia e contexto cultural coloca o importante problema do critério legitimador das mudanças que ocorreram nos séculos.

21 Ibidem, p. 8

22 SCHUSTER, Liber Sacramentorum: comento ascetico, storico, liturgico al Messale Romano. Torino: Marietti, 1920, v.1.

${ }^{23}$ Ibidem p. 7.

24 RIGHETTI, M. Manuale di Storia Litúrgica. Milano: Ancora, 1950. V. 1, p. 43.

25 NEUNHEUSER, B. Storia della liturgia e le epoche culturali. Roma : C.L.V. Edizioni Liturgiche, 1983. 
Como analisar essas mudanças? São obras do Espírito Santo, e, portanto, as consideramos de suma perfeição ou são criações humanas devido a uma explícita deliberação através do tempo? Cada época tem o direito de se exprimir em sua forma congenial, temos o direito e o dever de julgar se uma forma verdadeiramente responde as exigências de seu tempo e às normas supremas derivante da essência mesma do culto cristã $0^{26}$. 0 problema da essência do culto à luz do método histórico parece não demonstrar uma resposta adequada, a não ser recorrendo a critérios mais amplos, isto é, a investigação de ordem teológica e pastoral. Jungmann conforta esta tese atestando que historicamente as mudanças se explicam por motivos pastorais.

Onde encontrar a chave do mistério destas multíplices formas e tanto enigmáticas para nós. Esta alternação de lecionários, cantos e orações, toda esta riqueza de movimentos e cerimônias? Porque, sobretudo, esta multiplicidade de formas? A resposta se encontra na preocupação da autoridade eclesiástica pela Igreja e para a Igreja como totalidade dos fiéis, para a Igreja come plebs sancta, que sob a guia de seus pastores deve oferecer a Deus até que dure a existência terrena um serviço digno, na oração e no sacrifício, para santificar-se. Esta preocupação teve uma importância decisiva para a determinação da formação do culto ${ }^{27}$.

A indicação de Jungmann solicita uma resposta a um problema central já mencionado: de onde atrai a autoridade eclesiástica os critérios de reforma da liturgia? A pesquisa histórica revela mudanças também consistentes do culto no curso dos séculos, evidencia o momento de grave arbitrariedade na liturgia no presente, todavia, não é em grau de recolher as verdades dos ritos ou estabelecer leis. O maior limite o encontrou quando a prospectiva histórica passa a ser prospectiva teorética onicompreensiva, ou seja, quando se mede a verdade de um fenômeno somente em ordem ao significado histórico, tal fenômeno vem verificado em ordem a sua origem, que no caso da liturgia, pode ser bíblica, patrística, medieval, etc. Em tal modo se

26 Klauser reconhece que o método histórico é parte de um projeto hermenêutico que se ampliará no discurso teológico, veja: KLAUSER, T. La Liturgia nella strutturazione dela teologia. Rivista litúrgica, Roma, v. 58, n. 1, gen. 1971. Bimestral.

${ }_{27}$ JUNGMANN, J. Eredita litúrgica e attualita pastorale. Paoline: Roma, 1962, p. 557. 
move sobre o pressuposto que a verdade pertence ao passado e que se deve ser este passado o critério do presente. A superação de tal explicação genética da liturgia vem do mesmo campo histórico com introduções de problemáticas hermenêuticas. Rendemos conta que o histórico, verificando o fenômeno em ordem a sua origem, coloca em ato uma série de instrumentos de pesquisa que pertencem à consciência científica da época na qual se vive; ele procede verso ao passado partindo de um presente que o fornece a criteriologia para explicar e interpretar aquele passado. Propriamente, portanto, a via que conduz o passado ao presente é em posição dialética com aquela que procede do presente ao passado. De consequência, a verdade de tipo genético se demonstra uma ingenuidade. A razão principal de tal situação depende do fato que a verdade é o significado verificado sobre a base de uma experiência real; ora o histórico pode fazer emergir os significados registrados nos textos que estuda, mas não pode ir diretamente à experiência feita por aqueles que haviam produzido estes textos para verificar a validade em ordem ao real, a menos que também ele, estivesse presente, sendo dado a aceder aquele real.

Em campo litúrgico, o real é a historia da Salvação operada por Deus que se faz presente na celebração ritual. Trata-se, portanto, de passar da semântica histórica dos ritos à verdade teológica dos ritos, ou seja, da compreensão dos significados litúrgicos em ordem a documentação histórica dos ritos à compreensão da verdade litúrgica em ordem à real história da salvação.

Em síntese, a dimensão teológica da ciência litúrgica afirma que um dado significado litúrgico é verdadeiro se é fiel à realidade, que é a historia da salvação. Observa-se a confortante tese, que não aparece exagerada e nem unilateral, a estruturação do método histórico e a estruturação do método teológico, como base epistemológica adequada. Enquanto o histórico especifica o enquadramento contenuístico e cultural do rito em fase de permeabilidade antropológica, o teológico exibe a verdade sobre o fenômeno. 
Em conclusão se posiciona Marsili: "sem o aspecto teológico a liturgia seria somente reserva de caça para os históricos, arqueólogos, estéticos e cerimonialistas" 28 .

Tomamos em exame dois autores que representam a reflexão de maior nível teológico e que tem inciso em modo profundo e consistente sobre o recupero epistemológico da liturgia: C. Vagaggini e S. Marsili.

C. Vagaggini:

É surpreendente relevar da sua obra principal, o sentido teológico da liturgia, e o decisivo interesse epistemológico para a liturgia. Vagaggini entende superar a prospectiva jurídica, que reduz a ciência litúrgica a ser parte do direito canônico e oferece este contributo de prevalente linha histórica. Se antes a ciência litúrgica era considerada essencialmente como rubricista, hoje, na totalidade dos casos, é considerada essencialmente como simples história. Não que faltam acenos ao pensamento teológico ou ao valor ascético, espiritual e pastoral da liturgia, mas, se trata somente de acenos muito breves. A preocupação essencial vai ao aspecto histórico: a formação sucessiva da liturgia que temos hoje. Assim o ensinamento litúrgico se é esforçado a ser uma síntese de pesquisa histórica em torno à liturgia que teve a seu início científico com os grandes históricos do século XVII e tem feito progressos extraordinários desde o início deste século ${ }^{29}$.

Os resultados passaram a ser mais significativos desde quando passou da simples descrição histórica à interpretação do dado histórico: A gênese histórica do complexo litúrgico, sob todos os títulos e seus aspectos, leva a uma compreensão muito mais substancial da liturgia que hoje vivemos. E este objetivo vem alcançado tanto mais eficazmente, quanto mais o histórico se contenta em acertar os fatos e os estados sucessivos do objeto da sua pesquisa, mas se esforça também em demonstrar as forças externas e internas: cultural, espiritual, psicológicas, que os determinam e as constantes que se possam revelar, ou seja, os pontos de vista sintéticos que os rendem compreensíveis. Daí deriva em primeiro lugar que a continuação e o

\footnotetext{
28 MARSILI, S. Teologia Liturgica. Roma: Paoline, 1984.

29 VAGAGGINI, C. Il senso teológico dela liturgia: saggio di liturgia teológica generale, Roma: Paoline, 1957, p. 10.
} 
aperfeiçoamento destes estudos é evidentemente indispensáveis e os resultados das pesquisas históricas vem mantidos cuidadosamente presente para ulterior aprofundamento da liturgia ${ }^{30}$.

O apreço pelos resultados obtidos pela investigação histórica não impede o autor de procurar uma mais plausível definição de ciência litúrgica em torno a três diretivas: ascética, pastoral e teológica. 0 movimento litúrgico, sendo em si mesmo potentemente concentrado na investigação histórica na liturgia, da qual por sua vez recebe fortíssimo impulso, exige justamente ao mesmo tempo superar aquela fase histórica através: A Ascética, onde muito além de uma simples compreensão histórica, se desenvolve o fato humano lançado em uma fenomenicontologia.

A teológica que se ocupa com a pesquisa de aprofundamento da liturgia, conduzindo-a em ultima análise ao espaço disciplinar somente liderado pela teologia sintética geral, hoje denominada dogmática, adquirindo seu status de lócus teológico. Vagaggini não esconde a sua predileção por esta última e precisa a direção: Uma liturgia teológica deve impostar nitidamente todo o seu estudo no implícito da liturgia - a ação ritual -, para tocar no seu valor teológico. O aspecto histórico deve servir de base e pressuposto e o aspecto da vida espiritual e pastoral de consequência. Apreenderemos nesse método, uma liturgia teológica geral, promovendo o estudo do ponto de vista teológico, tratando dos elementos comuns e dos elementos singulares da liturgia; e uma liturgia teológica especial, que abordasse o estudo dos elementos especiais e também singulares: a Missa, o ano litúrgico, os sacramentos e os sacramentais ${ }^{31}$.

Levantando a questão das relações entre teologia e liturgia, o autor entende tratar a inserção da liturgia na teologia geral. $\mathrm{O}$ emprego de maior esforço é aquele de demonstrar que a liturgia contém o mesmo objeto da dogmática, isto é, o dialogo salvífico entre Deus e o homem. Diverso é só o modo, que na liturgia se desenvolve nas formas rituais.

30 Ib., p. 11.

31 Ibidem, p. 35. 
O limite do tentativo magistral de Vagaggini é de haver ligado demais a ciência litúrgica à teologia dogmática, sem suspeitar que a mesma compreenda referências próprias para exibir a sua fundação autônoma, também em ordem ao desenvolvimento da mesma dogmática.

Salvatore Marsili.

Este particular escapado a Vagaggini encontrou audiência na reflexão de S. Marsili, o qual não perseguiu uma "liturgia teológica”, mas uma "teologia litúrgica”, partindo do pressuposto da Igreja antiga em que a liturgia é theologia prima, o lugar da fé, onde a dogmática, o theologia secunda, atrai o material vivo para a sua reflexão ${ }^{32}$.Do ponto de vista epistemológico é o avesso a prospectiva de Vagaggini: a liturgia não funda a sua cientificidade na dogmática; ao contrário: a ciência litúrgica tem uma própria autonomia.

Não se trata, portanto, de conduzir a liturgia ao plano preferencial e nem menos como prato de dessert no encerramento do estar à mesa da teologia, mas se deve haver presente que o único Mistério de Cristo e a única Historia da Salvação, que a Escritura nos revela, como promessa e como fato, que a dogmática ilustra e expõe, e a moral ordena à pratica e execução, é - a nível de atuação e de realização sacramental - operante na Liturgia. No fundo se trata - tendo presente o aspecto de economia da revelação-salvação - de criar dois polos de atrações, que, se correspondem e se distinguem entre eles como dois momentos da mesma realidade: primeiro polo é a Escritura, que permanece sempre substancialmente revelação, mas vinda na diversidade de tempos e de lugares, tem a necessidade de uma reflexão teológica para uma compreensão a nível do nosso tempo (dogmática) e para uma pesquisa a nível da existência concreta, uma adequada resposta (moral); segundo polo é a liturgia, que é aquela mesma revelação que passa a ser acontecimento de salvação em ato, repreende - enquanto continuada atuação do Mistério Cristo - o papel já assumido por Cristo-Palavra feito carne. Aqui o anúncio se soma a realidade ${ }^{33}$.

32 MARSILI, S. Il simbolismo dela iniziazione Cristiana ala luce dela storia litúrgica. Studia anselmiana Analecta litúrgica, Roma, v. 87, n. 7, gen. 1983. Semestral.

33 Ib. p. 162. 
A relação entre liturgia e teologia é incindível porque a reflexão sobre a História da Salvação em ato na liturgia é já sempre teologia; da outra parte, a reflexão teológica tem necessidade de ancorar no evento salvífico atual, como se oferece no culto.

Próprio porque a liturgia como expressão da fé, quase inevitavelmente assume função de teologia, enquanto é repensamento da realidade de fé, vista sobre o plano de atuação ritual. Dizendo que a teologia deve ser litúrgica, nós liturgistas entendemos afirmar duas coisas, isto é que o sujeito da reflexão teológica deve ser reconduzido à sua natural posição, aquela do acontecimento ou do evento atual, como se apresenta na liturgia; acontecimento e evento que devem ser considerados como tal, isto é, não como verdade abstrata, mas como realidade econômica, vale dizer como realidade divina e em função humana atual.

A teologia litúrgica não é aquela que assume os traços teológicos da celebração para construir uma teologia de fundo litúrgico; nem mesmo é aquela que assume da liturgia provas para corroborar os textos dogmáticos. A teologia litúrgica é o discurso sobre Deus, não enquanto letra, mas enquanto agir se funda o que chamamos de "sacramentalidade". E o Deus objeto da teologia é somente o Deus da revelação. A revelação não é unicamente a manifestação da verdade de Deus e sobre Deus, enquanto existente em Deus, mas é comunicação/ participação de Deus enquanto realidade salvífica para o homem, e como tal não pode realizar-se senão através da via da sacramentalidade, isto é, por meio de um símbolo que revele Deus e a sua realidade salvífica comunicante.

Teologia litúrgica é, portanto, aquela que faz o próprio discurso sobre Deus partindo da revelação, vista na sua natureza de fenômeno sacramental, no qual convergem o acontecimento da salvação e o rito litúrgico que o representa. Em tal modo a teologia litúrgica é necessariamente a primeira de tudo na economia divina, isto é, da presença e da ação de Deus no mundo, que no mundo quer realizar-se como salvação eterna em dimensão antropológica. Isto aconteceu em sinal profético no Antigo Testamento e em sinal real no Novo Testamento, antes em Cristo, sacramento humano de Deus na encarnação, depois 
nos homens, aos quais Cristo comunica com sacramentos singulares e distintos a si mesmo, sacramento total de salvação.

Pensamos que ao interno da sacramentalidade geral, a ciência litúrgica pode talhar o seu espaço autônomo, que consiste na interpretação teológica da celebração ritual, que Ruffini chama particularíssima encarnação da Graça em forma ritual que constitui o objeto especifico da ciência litúrgica ${ }^{34}$.

Em época de grande revelo da dimensão antropológica, em particular, os símbolos, os sinais, os gestos celebrativos e rituais, a celebração da ritualidade cristã precisa ser suscetível a uma série de reflexões interessantes de interpretação teológica, a exemplo da própria teologia dogmática que está descobrindo o significado salvífico dos valores antropológicos, até sublinhar a possibilidade de uma leitura lúdica, isto é, em prospectiva tipicamente ritual, de todo o patrimônio doutrinário cristão, a liturgia precisa recorrer à análise de natureza e formalidade da celebração.

Marsili parece orientar a sua pesquisa nessa direção quando define a liturgia: "Uma ação sagrada através da qual, com um rito, na Igreja e mediante a Igreja, vem exercitada e continuada o obra sacerdotal de Cristo, isto é, a santificação dos homens e a glorificação de Deus" 35 .

A reflexão de Marisli sobre a praxe ritual é atenta para não permitir o precipitar da liturgia na mera antropologia e nos reduza a uma prática ou a uma pesquisa em que a antropologia, enquanto aplicação à liturgia implique aquelas leis e modalidade psico-sociológica de comportamento (gestualidade, oralidade, ritualidade, uso do símbolo) como o dado exclusivo por meio do qual o evento salvífico encontre concreta ressonância e atuação no sujeito ${ }^{36}$.

0 rito entra necessariamente no conceito de liturgia; em cada culto as formas da celebração são sempre expressão simbólica de uma realidade que está além da forma. Mas enquanto no culto natural o rito é símbolo da realidade religiosa do homem, o regime

\footnotetext{
34 RUFFINI, E. Teologia dei sacramenti e liturgia in Teologia e Liturgia: rapporti interdisciplinare e metodologici. Bologna: EDB, 1974, p. 108.

35 Marsili segue a mesma sensibiidade, Ib, p. 733.

36 MARSILI, Ibidem, p. 271.
} 
simbólico pelo qual é constituída a liturgia, compreende antes de tudo como primeira tarefa exprimir na ação da Igreja, o mesmo culto que Cristo rendeu ao Pai na sua vida. É em força do sinal simbólico que a liturgia é mistério do culto de Cristo, os seus símbolos são de fato aquele que para Cristo era a sua humanidade; no sentido que o culto oferecido por Cristo ao Pai imediatamente na sua humanidade, ora é oferecido com a mediação do rito, o qual reveste a sua natureza e função sacramental, a liturgia cristã não pode haver ritos se não são símbolos de Cristo, e tudo aquilo que é simbólico de Cristo e de sua ação salvífica encontra no Antigo e no Novo Testamento uma única tese: a transformação do homem.

O rito litúrgico é a carne de Cristo para nós, esta precisão é fundamental para o diálogo com as ciências humanas e para aquisição de uma pista epistemológica atendível que inconteste nossa invasão neste campo de estudo, para permanecermos defronte o exame em relação: materialidade e simbolismo fatos da natureza do homem que se expõe no rito. O problema epistemológico da ciência litúrgica pensado neste tempo do pós-Concílio, provoca a teologia a demonstrar a sua capacidade de ampla dissertação sobre a sua mesma cientificidade evitando uma "ontologia militante".

A inserção da antropologia sociocultural e a observação não periférica de suas escolas que superaram o funcionalismo e se orientam verso o simbólico, demonstram resultados de pesquisas para a interpretação cultural que merecem uma dedicada atenção da parte da teologia, sobretudo em suas exposições onde demonstram com clareza como o rito é modelo metodológico para interpretação das culturas, onde a hermenêutica se abre ao nível semântico e inicia sua investigação nas extensões das formas simbólicas abordando as seguintes fases:

- O problema epistemológico se resolve no problema da fundamentação.

- Não se dá fundamentação fora da hermenêutica.

- A hermenêutica deve passar através do conflito da interpretação rival.

- A hermenêutica precisa da fenomenologia para superar o neo-idealismo. 
- O ponto de partida para cada hermenêutica é a linguagem.

Na composição deste quadro o conteúdo unitário é o rito, onde se exprime a globalidade do homem religioso, suscitando suas aspirações transcendentes que se exprimem na linguagem simbólica. A percepção dessa linguagem é o inicio da leitura sobre esse homem e inicio da compreensão da interpretação que ele mesmo tem sobre o que ele mesmo celebra.

A dinâmica reflexiva não é funcionalista, não se trata de uma interpretação do homem simplesmente a partir da performance ritual operada pelo pesquisador, se trata sim de o pesquisador compreender a interpretação que próprio homem elabora e o pesquisador simplesmente lê, não interfere.

Neste âmbito nuclear se encontra a originalidade e aqui surgem as primeiras pistas para conduzir um programa de pesquisa sociocultural: a linguagem homem exibida nas formas rituais e a sua produção hermenêutica.

Tentamos reconhecer e sugerir que a atividade teológico-litúrgica, seguindo o referimento do Vaticano II, encontra a este ponto o lugar de dialogo com as ciências humanas e um suporte epistemológico aceitável: o rito como tradução do homem e da sua cultura.

\section{Conclusão}

Recorrendo ao modo figurativo para apresentar nossas considerações finais, vemos que a Liturgia aparece muitas vezes como a "Cinderela"; assim como na famosa fábula, ela de fato, cumpre os trabalhos sem os quais a grande casa habitada sem ela andaria em ruínas, mas, como sempre esta figura, não participa do dialogo com os outros inquilinos. A praxe litúrgica é como o "sangue" que escorre nas veias da inteira comunidade cristã, mantendo comunhão com o seu próprio fundamento e nutrindo continuamente os membros que a compõe; mas vemos, também, notáveis situações de contradições, a Liturgia não desenvolve ainda um papel relevante no dialogo teológico.

A Linguagem simbólico-ritual do sagrado vem apresentada repetidamente ao centro da atenção da nossa reflexão, quase a declinar constantemente o encontro entre o homem e Deus, preserva-nos da 
blasfêmia de eliminar a diferença: o “dizer Deus” da fé é autentico se não se perde o "silêncio humano" do rito. O rito litúrgico eclesial não responde a essência da transcendência, mas faz a transcendência, produz um "salto" que se livra da habitual lógica determinações (loucura da cruz de Paulo Apostolo) e introduz em "um espaço não espaço" onde prevalece o mistério.

A experiência litúrgica, precisa superar o que marcou cada sistema simbólico ligado ao poder politico e econômico, orientando-se como consequência especifica a colocar-se diante do fenômeno religioso contemporâneo, percorrendo em base as orientações do Vaticano II, uma leitura profunda sobre o homem e sua cultura, auxiliada pelas investigações cientificas das áreas de ciências humanas, sobretudo, o campo da antropologia sócio cultural e seus novos métodos interpretativos, como a performance, abrindo novos horizontes verso a linguagem simbólica e a semiótica, que superaram definitivamente as velhas escolas de antropologia funcionalistas.

\section{Bibliografia}

ARISTOTELES. Metafísica. Torino: UTET, 1974.

BECKETT, S. Compagnia e Worstward. Milano: Jaca Book, 1986.

BIBBIA DI GERUSALEMME. Roma: Paoline, 2000.

BORNKAMN, G. Storia e Fede. Bologna: EDB, 1970.

CAZELLES,H. Eucharistie, bénédiction et sacrifice dans l'Ancien Testament. La Maison-Dieu, Paris, v. 1, n. 75, giun. 1975. Bimestral.

CHENU,M. D. Puor une anthropologie sacramentelle? La Maison-Dieu, Paris, v. 3, n. 71, jan. 1974. Bimestral.

DARLAP, A. Mysterium Salutis: compendio di dogmatica storico-salvifica. Brescia: Queriana, 1974. v. 1/2.

EISENHOFER, L. Compendio di Liturgia. Torino: Marietti, 1941.

FEYERBEND, P.K. Contro il método. Milano: Felttrinelli, 1980.

FOHRER, G. Strutture teologiche dell'Antigo Testamento. Brescia: Padéia, 1980.

GADAMER, H. G. Studi Platonici. Casale Monferrato: Marietti, 1983. v. 1. GADAMER, H.G. Ermeneutica e metodica universal. Torino: Marietti, 1973. 
GIRAUDO, C. La struttura letteraria della preghiera eucaristica: saggio sulla genesi di una forma. Roma: Roman Biblical Institute Press, 1981. JEREMIAS, J. Le parole dell'ultima cena. Brescia: Paidéia, 1973.

JUNGMANN, J. Eredita liturgica e attualita pastorale. Paoline: Roma, 1962. KLAUSER,T. La liturgia della chiesa occidentale. Torino: Elle Di Ci, 1971. MARSILI, S. La Liturgia nella strutturazione della teologia. Rivista liturgica, Roma, v. 58, n. 1, gen. 1971. Bimestral.

MARSILI, S. Il simbolismo della iniziazione Cristiana alla luce dela storia litúrgica. Studia anselmiana Analecta litúrgica, Roma, v. 87, n. 7, gen. 1983. Semestral.

MARSILI, S. Liturgia. In: NUOVO Dizionario di Liturgia. Roma: Paoline, 1984.

MARSILI, S. Teologia Liturgica. Roma: Paoline, 1984.

MEYER, H. Elementi mutabili ed elementi vincolanti nelle forme liturgiche. Concilium, Milano, v. 5, n. 1, febb. 1969. Semestral.

NEUNHEUSER, B. Storia della liturgia e le epoche culturali. Roma: C.L.V. Edizioni Liturgiche, 1983.

PERROT, C. Le repas du Seigneur. La Maison- Dieu, Paris, v. 123, n. 2, feb. 1975.

PIO XII, Papa. Mediator Dei. Cidade do Vaticano, 1947.

RENNINGS, H. La scienza litúrgica. Concilium, Milano, v. 5, n. 2, giun. 1969. RIGHETTI, M. Manuale di storia liturgica. Milano: Ancora, 1950. v. 1.

RIZZI. A. Differenza e responsabilità: saggi di antropologia teologica. Casale Monferrato: Marietti, 1983.

RUFFINI. E. Teologia dei sacramenti e liturgia in Teologia e liturgia: rapporti interdisciplinare e metodologici. Bologna: EDB, 1974.

RUFFINI. E. LODI. E. Misterium e sacramentum: a sacramentalita negli scritti dei Padri e nei testi liturgci primitivi. Bologna: EDB, 1987.

SCHUSTER, Liber Sacramentorum: comento ascetico, storico, liturgico al Messale Romano. Torino: Marietti, 1919. v. 1.

SCHNIEWIND. I, Leitourgia e Mistero. Milano: Jack Book, 1972.

VAGAGGINI. C. Il senso teologico della liturgia: saggio di liturgia teologica generale, Roma: Paoline, 1957.

Recebido em: 25/11/2014

Aprovado em: 09/05/2015 